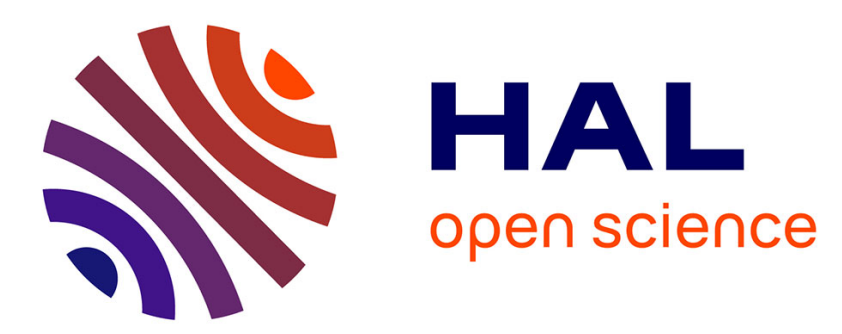

\title{
Attribution of Extreme Wave Height Records along the North Atlantic Coasts using Hindcast Data: Feasibility and Limitations
}

Jeremy Rohmer, Jessie Louisor, Gonéri Le Cozannet, Philippe Naveau, Soulivanh Thao, Xavier Bertin

\section{To cite this version:}

Jeremy Rohmer, Jessie Louisor, Gonéri Le Cozannet, Philippe Naveau, Soulivanh Thao, et al.. Attribution of Extreme Wave Height Records along the North Atlantic Coasts using Hindcast Data: Feasibility and Limitations. Journal of Coastal Research, 2020, 95 (sp1), pp.1268-1272. 10.2112/SI95-

245.1. hal-02844118

\author{
HAL Id: hal-02844118 \\ https://hal.science/hal-02844118
}

Submitted on 24 Jun 2020

HAL is a multi-disciplinary open access archive for the deposit and dissemination of scientific research documents, whether they are published or not. The documents may come from teaching and research institutions in France or abroad, or from public or private research centers.
L'archive ouverte pluridisciplinaire HAL, est destinée au dépôt et à la diffusion de documents scientifiques de niveau recherche, publiés ou non, émanant des établissements d'enseignement et de recherche français ou étrangers, des laboratoires publics ou privés. 


\title{
Attribution of Extreme Wave Height Records along the North Atlantic Coasts using Hindcast Data: Feasibility and Limitations
}

\author{
Jérémy Rohmer, Jessie Louisor, Gonéri Le Cozannet, Philippe Naveau, \\ Soulivanh Thao, Xavier Bertin
}

\section{To cite this version:}

Jérémy Rohmer, Jessie Louisor, Gonéri Le Cozannet, Philippe Naveau, Soulivanh Thao, et al.. Attribution of Extreme Wave Height Records along the North Atlantic Coasts using Hindcast Data: Feasibility and Limitations. Journal of Coastal Research, Coastal Education and Research Foundation, 2020, 95 (sp1), pp.1268-1272. 10.2112/SI95-245.1 . hal-02844118

\section{HAL Id: hal-02844118 \\ https://hal.archives-ouvertes.fr/hal-02844118}

Submitted on 24 Jun 2020

HAL is a multi-disciplinary open access archive for the deposit and dissemination of scientific research documents, whether they are published or not. The documents may come from teaching and research institutions in France or abroad, or from public or private research centers.
L'archive ouverte pluridisciplinaire HAL, est destinée au dépôt et à la diffusion de documents scientifiques de niveau recherche, publiés ou non, émanant des établissements d'enseignement et de recherche français ou étrangers, des laboratoires publics ou privés. 


\title{
Attribution of extreme wave height records along the North Atlantic coasts using hindcast data: feasability and limitations.
}

\author{
Jeremy Rohmer $^{\dagger *}$, Jessie Louisor ${ }^{\dagger}$, Goneri Le Cozannet ${ }^{\dagger}$, Philippe Naveau ${ }^{\dagger \dagger}$, \\ Soulivanh Thao ${ }^{\dagger \dagger}$, and Xavier Bertin ${ }^{\dagger}$ \\ ${ }^{\dagger}$ BRGM \\ French geological survey \\ Orleans, France \\ ${ }^{\dagger}$ LSCE/IPSL, CEA-CNRS-UVSQ $\quad$ UMR 7266 LIENSs, CNRS \\ Paris-Saclay university \\ Gif-sur-Yvette, France \\ La Rochelle university \\ La Rochelle, France
}

\begin{abstract}
Rohmer, J.; Louisor, J.; Le Cozannet, G.; Naveau, P.; Thao, S.; and Bertin, X., 2020. Attribution of extreme wave height records along the North Atlantic coasts using hindcast data: feasibility and limitations. In: Malvárez, G. and Navas, F. (eds.), Proceedings from the International Coastal Symposium (ICS) 2020 (Seville, Spain). Journal of Coastal Research, Special Issue No. 95, pp. 50-54. Coconut Creek (Florida), ISSN 0749-0208.

Extreme Event Attribution (EEA) aims at answering questions about how much climate change influenced the probability or intensity of a specific type of extreme meteo-oceanic event. Here, we focus on wave record breaking i.e. the occurrence of an extreme significant wave height $(h s)$ value that exceeds all past observations. The objective is to evaluate the probability changes related to climate change by estimating the fraction of attributable risk far=1$p_{0} / p_{1}$, where $p_{0}$ and $p_{1}$ are probabilities of the wave record event in two different worlds: a counterfactual world without anthropogenic forcings i.e. a "world that might have been", and the "world that is" so called factual world. To define these different worlds, we rely on a wave hindcast database, which provides very long time series (19002008) of $h s$ over the whole North Atlantic Ocean Basin (NAOB). We assume that the counterfactual world corresponds to the series of annual $h s$ maxima over the period 1900-1930, and that the factual world corresponds to the annual $h s$ maxima over the period 1978-2008. The extreme event attribution approach dedicated to record breakings was applied over NAOB, and we show large far values $(>0.5)$ along the northern Canadian, Scottish and southwestern Norwegian coasts (over the latitudes $50^{\circ}-65^{\circ} \mathrm{N}$ ). These results are, however, carefully discussed with respect to different uncertainty sources, namely the validity of the assumptions underlying the EEA, the statistical uncertainties, the use of hindcast data instead of global climate model's results, and the limitations in the hindcast database setup.
\end{abstract}

KEYWORDS: Climate Change, Extreme Event Attribution, Wave, Fraction of Attributable Risk, Uncertainties.

\section{INTRODUCTION}

The task of attribution can be defined following Bindoff et al. (2013) as the process of evaluating the relative contributions of multiple causal factors to a change or event with an assignment of statistical confidence. In other words, event attribution aims at answering questions about how much climate change influenced the probability (or intensity) of a specific type of weather event. Different methods to detect and attribute a human influence in the change of likelihood of extreme events have been developed (see Stott et al. 2016 for a review) with applications to different types of natural phenomena like hurricane-induced heavy rainfall, e.g., van Oldenborgh et al. (2017); heat waves: e.g., Hauser et al. (2017), Otto et al. (2012), etc.

The present study is focused on a risk-based extreme event attribution (EEA) approach, which aims at evaluating the probability changes of an extreme event related to climate change. This approach is based on the estimate of the risk ratio $R R=p_{1} / p_{0}$,

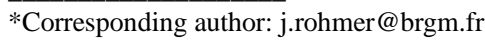

where $p_{0}$ and $p_{1}$ are probabilities of the same event, but under two different situations: a "world that might have been" (a counterfactual world without anthropogenic forcings) and the "world that is" (a factual world). The fraction far $=1-1 / R R$ then measures the proportion of the current risk that is attributable to past greenhouse gas emission (see e.g., Stott et al. 2016). If far significatively differs from 0 (i.e. with high confidence), this means that factors / processes present in the factual world (and absent in the counterfactual world) have changed the probability of the considered event.

Different statistical methods and approaches have been developed for EEA (Naveau et al. 2019), and in the present study, we rely on the EEA method recently developed by Naveau et al. (2018) to deal with record breakings, i.e. the event of interest is the occurrence of an observation that exceeds all past observations. We focus on extreme sea states, characterized by high significant wave height (denoted $h s$ ) and aims at estimating the far indicator regarding the record breaking for annual $h s$ over the North Atlantic ocean basin (denoted NAOB). A careful attention is paid to discuss the results with respect to different uncertainties, namely the validity of the assumptions underlying the EEA, the statistical uncertainties, the use of hindcast data instead of Global Climate model's results, and the limitations related to the hindcast database setup.

\section{METHODS}




\section{Data}

The key ingredient of any EEA is the definition of a counterfactual world. There are different possible ways by making use of : (i) past historical observations; (ii) climate models in the historical period; (iii) climate models with preindustrial runs; (iv) climate models where greenhouse gas emissions have been removed, etc. (see an exhaustive review by Jézéquel et al. 2018). For wave heights, the use of observations is hindered by the starting date, which is often incompatible with the counterfactual assumptions, whether for buoy data (whose spatial resolution can also be a limitation), or for satellite data (with starting date often in the 80s, see e.g., Young and Ribal (2019)) or for visual observations (like wave height derived from Voluntary Observing Ships, see e.g. Gulev and Grigorieva 2004). Sea state characteristics are not directly computed by climate models, which can hardly be used as such for wave EEA contrary to other variable of interest like temperature (e.g., Otto et al. 2012). Therefore, we rely on the wave hindcast dataset by Bertin et al. (2013), which has the advantage of a very large temporal coverage (1900-2008) as well as a large spatial coverage over NAOB (Figure 1).

The numerical hindcast is based on a regional implementation of WaveWatch III spectral wave model (Tolman 2009), forced with 3-hourly wind fields originating from the 20CR reanalysis V2 (Compo et al. 2011). The data used in this study consist of 6hourly time-series of significant wave heights $h s$ over the North Atlantic Ocean $\left(80^{\circ} \mathrm{W}-10^{\circ} \mathrm{E} ; 0^{\circ} \mathrm{N}-80^{\circ} \mathrm{N}\right)$ at $1^{\circ} \times 1^{\circ}$ spatial resolution. From the hindcast dataset, we extracted the annual maximum values of $h s$ over the whole basin. To represent the factual and counterfactual worlds, the time series at each spatial location of the model grid is divided into two parts: 1900-1930 and 1978-2008. Figure 1a,b provides the maxima for the counter- and the factual period, respectively. From a mere visual inspection, we can notice that changes in the spatial extent of the region where $h s>10 \mathrm{~m}$ appears to be larger in the factual period.

\section{Extreme event attribution (EEA) approach}

Full details on the EEA methods are available in (Naveau et al. 2018). We recall here the main assumptions.

Consider a time series $\mathbf{Y}=\left(Y_{1}, Y_{2}, \ldots, Y_{\mathrm{k}}\right)$ of annual data (that are assumed to be independently and identically distributed). The year $r$ is considered a record if $Y_{\mathrm{r}}>\max \left(Y_{1}, Y_{2}, \ldots, Y_{\mathrm{r}-1}\right)$. Let us denote $\mathbf{Z}=\left(Z_{1}, Z_{2}, \ldots, Z_{\mathrm{k}}\right)$ and $\mathbf{X}=\left(X_{1}, X_{2}, \ldots, X_{\mathrm{k}}\right)$ the time-series of the variable of interest in the factual world and the counterfactual world respectively. The probably $p_{0, \mathrm{r}}$ of having a record after a sequence of length $\mathrm{r}-1$ in the counterfactual world is $1 / \mathrm{r}$. The probability $p_{1, \mathrm{r}}$ is the probability that an a realization of $Z_{\mathrm{r}}$ in the factual world have been a record in the counterfactual world if $(\mathrm{r}-1)$ values of $X_{\mathrm{r}}$ were already observed. It is assumed to be written as follows:

$$
p_{1, r}=\mathrm{E}\left(G(Z)^{r-1}\right)=\mathrm{E}(\exp (-(\mathrm{r}-1) \mathrm{W}))
$$

where $\mathrm{E}($.$) is the expectation, G$ is the cumulative distribution function $(\mathrm{CDF})$ of $\mathbf{X}$ and $W$ is random variable derived as follows:

$$
W=-\log (G(Z))
$$

By assuming that $W$ follows a exponential distribution of mean $\theta$, the probability $p_{1, \mathrm{r}}$ holds as follows:

$$
p_{1, r}=\frac{1}{1+(r-1) \theta}
$$

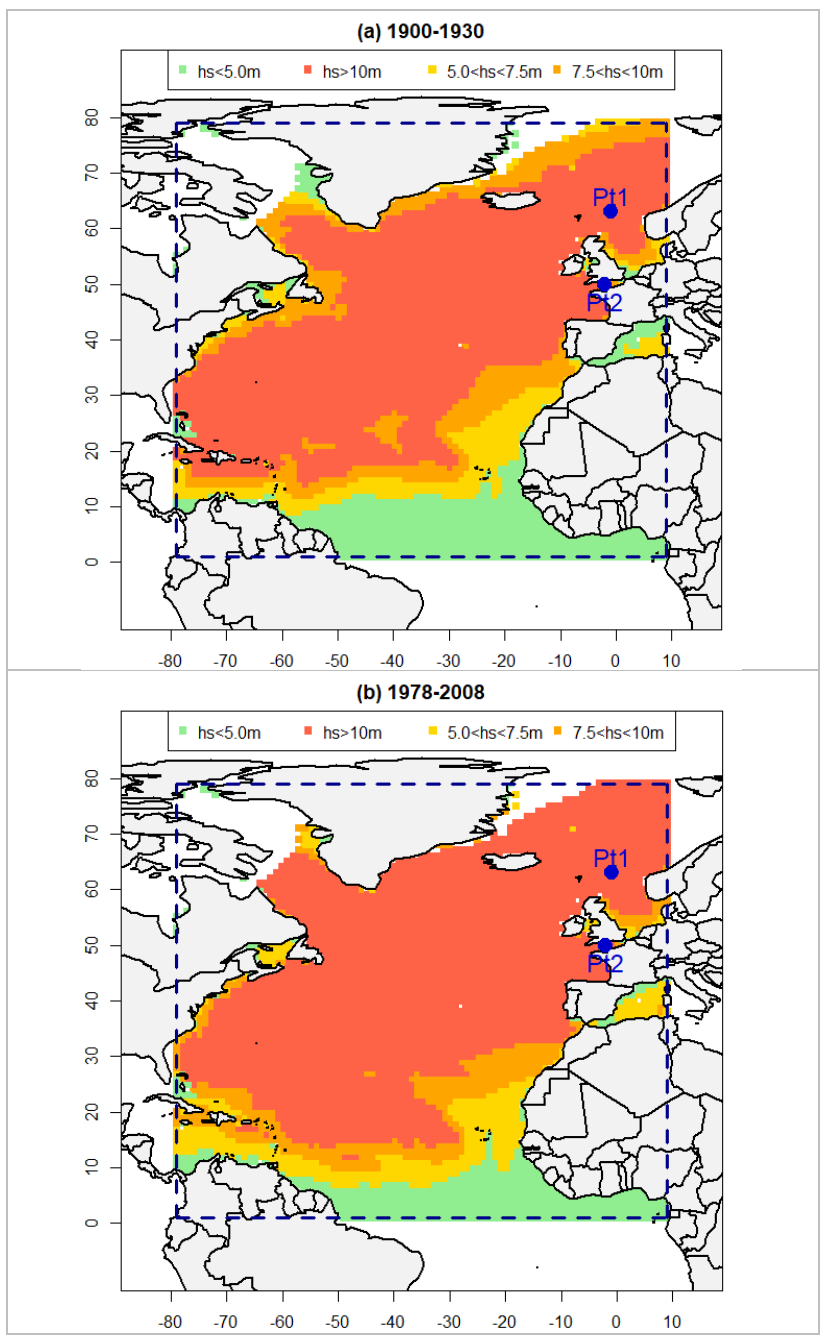

Figure 1. Spatial evolution of the maximum $h s$ values over the North Atlantic Ocean Basin (domain boundaries are outlined by dashed blue lines) (a) for the counterfactual world defined over the time period 19001930; (b) for the factual world defined over the time period 1978-2008. The observation points $\mathrm{Pt}_{1}$ and $\mathrm{Pt}_{2}$, where the analysis of Figures 2 and 3 are conducted, are outlined by blue dots.

Naveau et al. (2018) provide formulae to infer $\theta$ from the empirical estimator of $G$ as well as the associated uncertainty (using the delta method). Based on $p_{1, \mathrm{r}}$ and $p_{0, \mathrm{r}}$, the far indicator can be evaluated to measure to which extent the occurrence probability of the record has changed between the counter- and the factual world. 


\section{RESULTS}

The EEA procedure is first applied on the $h s$ time series (Figure 2a, 3a), at two specific locations, namely at $\mathrm{Pt}_{1}=\left(-1^{\circ}\right.$; $\left.63^{\circ}\right)$ close to the North of the scottish coasts, and at $\mathrm{Pt}_{2}=\left(-2^{\circ}\right.$; $50^{\circ}$ ) at the entrance of the English channel (see locations in Figure 1).

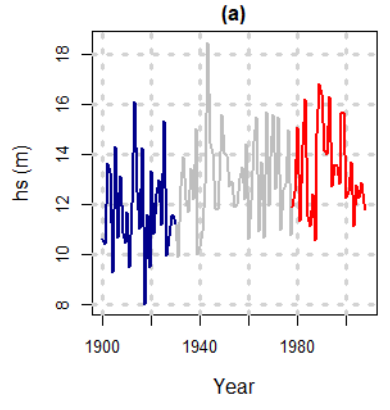

(c)

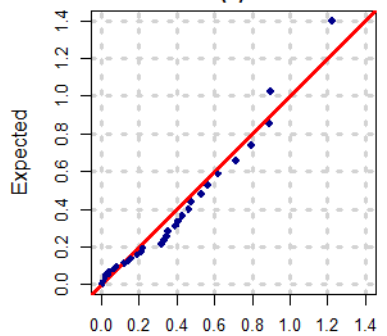

Observed

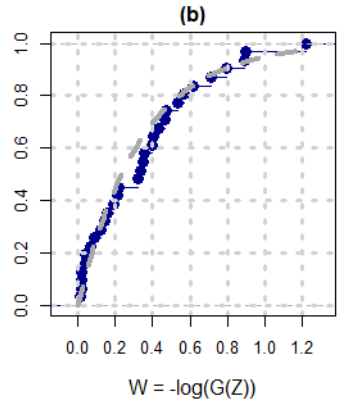

(d)

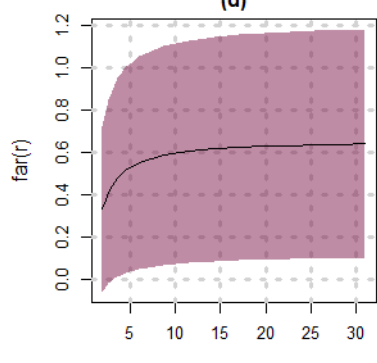

Return period $\mathrm{r}$
Figure 2. (a) Time series of $h s$ at the location at $\mathrm{Pt}_{1}=\left(-1^{\circ} ; 63^{\circ}\right)$. In blue: counterfactual data. In red: factual data; (b) Comparison between theoretical and empirical CDFs for the random variable $W$; (c) Exponential QQ plot; (d) far evolution depending on the considered return period $r$. The shadded area represents the $90 \%$-confidenceinterval band for the estimated far.

Considering the first location $\mathrm{Pt}_{1}$, Figure $2 \mathrm{~b}$ shows that the cumulative distribution function $\mathrm{CDF}$ of the transformed random variable $W$ (eq. 2) is well modelled by an exponential function. This is also confirmed by examining the alignment of the dots in the QQ plot of Figure 2c. The validity of the assumption of the exponentiality for $W$ is further supported by the test of Cox and Oates (1984), which yields a large p-value of $\sim 70 \%$, i.e. superior to the significance threshold chosen here at $5 \%$. This indicates that there is no reason to reject the exponential model. On this basis, the evolution of far depending on the choice of a particular return period $r$ is computed (Figure 2d) together with the $90 \%$-confidence-interval band. On this basis, we can deduce that $\operatorname{far}(r)$ is significantively different from zero with a value reaching around 0.6 (for $r=31$ years). This value is associated with high confidence, because the lower bound of the $90 \%$-confidence interval significatively exceeds zero.

Considering the second location $\mathrm{Pt}_{2}$, the same analysis is perfomed. Figure $3 b, c$ support the assumption of the exponentiality of the transformed random variable $W$. This is also supported by the large p-value of $\sim 60 \%$ for the test of Cox and Oates (1984). Figure 3d depicts the evolution of far depending on the considered return period $r$ together with the $90 \%$-confidence-interval band. Here, we can deduce that $\operatorname{far}(r)$ reaches around 0.5 (for $r=31$ years). Yet, contrary to Figure 2, the confidence in this resul is lower, because the lower bound of the confidence interval is lower than zero while the upper bound is non-zero. This uncertainty in the estimates prevents us from drawing a firm conclusion on the attribution.
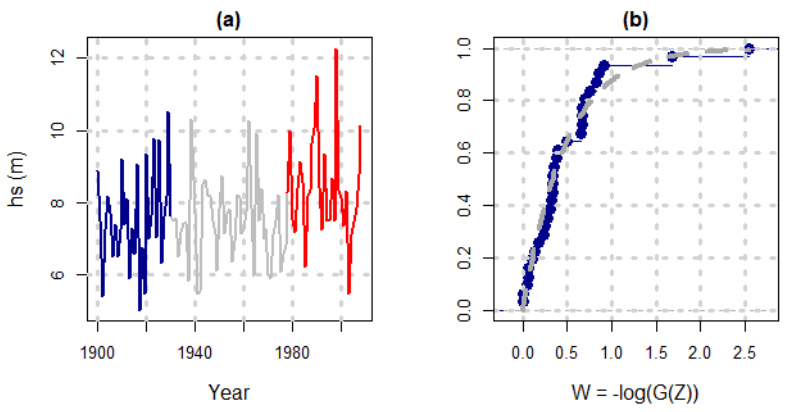

(c)

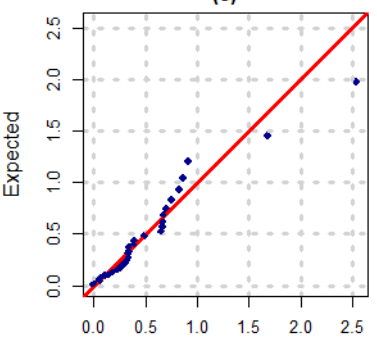

Observed

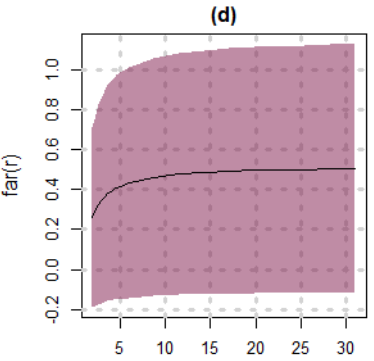

Return period $\mathrm{r}$

Figure 3. (a) Time series of $h s$ at the location at $\mathrm{Pt}_{2}=\left(-2^{\circ} ; 50^{\circ}\right)$. In blue: counterfactual data. In red: factual data; (b) Comparison between theoretical and empirical CDFs for the random variable $W$; (c) Exponential QQ plot; (d) far evolution depending on the considered return period $r$. The shadded area represents the 90\%-confidenceinterval band for the estimated far.

The analysis is conducted at all spatial locations of the NAOB. Figure 4 shows the far estimates for $r=31$ years. This indicates that the northern part of NAOB and the coasts of the northwestern part of Africa present significant far estimates superior to $50 \%$. Interestingly, the wave height on the European Atlantic coasts (SW of France and NW of Spain, and Portugal) appear to be affected only moderatevily (far ranges from 0.25 to $\sim 0.50$ ). The far estimates over the eastern part of the US appear to be of low values $10 \%$.

The results of Figure 4 should, however, be carefully discussed with respect to different uncertainties.

\section{DISCUSSION}

\section{Assumptions of the EEA approach}

First, Figure 4 is derived without analysing the key assumption of the EEA approach, namely the validity of the exponentiality of $W$. Figure 5 now shows the far estimates (for $r=31$ years) by restricting to the locations where the $p$-values of the test of Cox and Oates (1984) exceeds the significance threshold of $5 \%$. This clearly indicates that the exponentiality underlying the EEA approach is only valid in the northern part 
of NAOB, in the northeastern part of South America and over the coasts of the northwestern part of Africa.

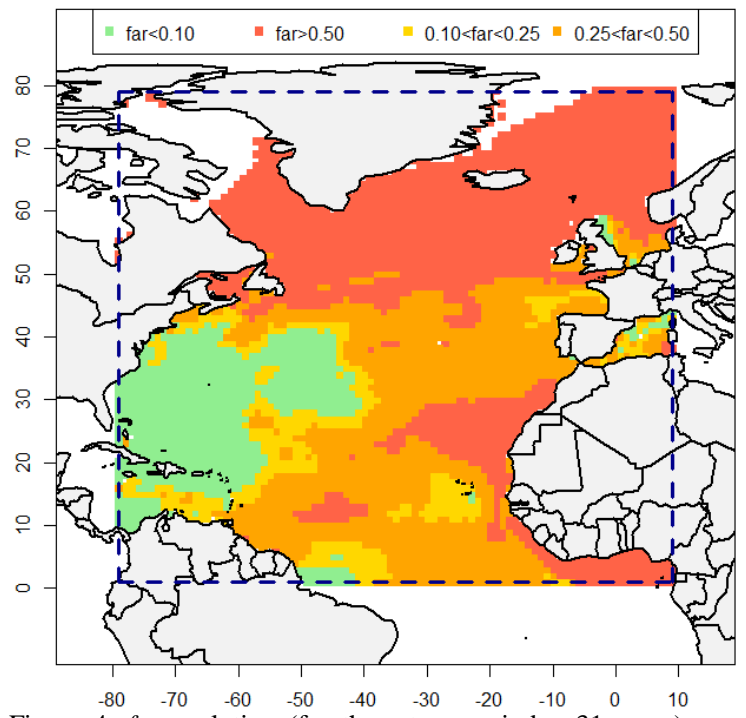

Figure 4. far evolution (for the return period $r=31$ years) over the North Atlantic Ocean.

\section{Statistical uncertainties}

As illustrated in Figure 3d, a non-zero far value does not necessarily mean high confidence in the estimate, because the lower bound of the confidence interval may fall below zero. To account for this problem, we update the results of Figure 5 by selecting only the locations where the lower bound of the $90 \%$ confidence interval exceeds zero. Figure 6 shows that a large majority of the selected regions of Figure 5 have been filtered out, and more particulary the European Atlantic coasts where the far estimates were only of moderate values (over the range 25$50 \%$ ).

Figure 6 shows that only the waves in the vicinity of the northern Canadian, Scottish and southwestern Norwegian coasts (over the latitudes $\sim 50^{\circ}-65^{\circ} \mathrm{N}$ ), as well as the Western Sahara, appear to present significant far estimates with high confidence.

The analysis was re-conducted by considering two alternative return periods, namely $\mathrm{r}=11$ and 41 years, and the conclusions were similar (though we noted some slight changes in the spatial extent of the red coloured envelope in Figure 6).

\section{Use of hindcast data}

The findings of Figure 6, though robust regarding the assumptions of the considered EEA approach (as well as the statistical uncertainties), should be carefully analysed by keeping mind that the results are based on the use of hindcast data by Bertin et al. (2013).

First, the use of this type of data raises the question of the uncertainties related to the numerical model. Due to computational time and data storage limitations, Bertin et al. (2013) restricted the analysis on the ensemble-mean of the $20^{\text {th }}$ century reanalysis to force their hindcast. This could question the accuracy of wave predictions for the early part of the 20th compared to the atmospheric reanalyse that best represents extreme waves, particularly for high percentiles. Yet, Fortunato et al. (2017) showed that, in the NE Atlantic Ocean, this wave hindcast had satisfactory root mean squared discrepancies on $h s$ ranging from 16 to $24 \%$, without any particular bias for high percentiles. Such values provide a similar accuracy compared to wave hindcast forced with the popular NCEP reanalysis (e.g. Dodet et al. 2010). This brings additional elements for confidence in the results of Figure 6 . The influence of boundary conditions of the numerical model should however be highlighted for regions below latitude $20^{\circ} \mathrm{N}$, which might influence the far estimates for Gulf of Ginea: the results are here considered of low confidence.

Second, the results are presumably strongly dependent on how the counterfactual world is defined. Here, it is based on the 1900-1930 time period of the hindcast dataset. In this sense, the results do not give a complete account of the effects of climate change, because the world of the past (i.e. before 1930) might already have been affected by anthropogenic emissions. A significant non-zero estimate in our study only means that processes / factors acting in the factual worlds (here 1978-2008) have led to changes of the probability of the breaking records (w.r.t. the counterfactual world 1900-1930).

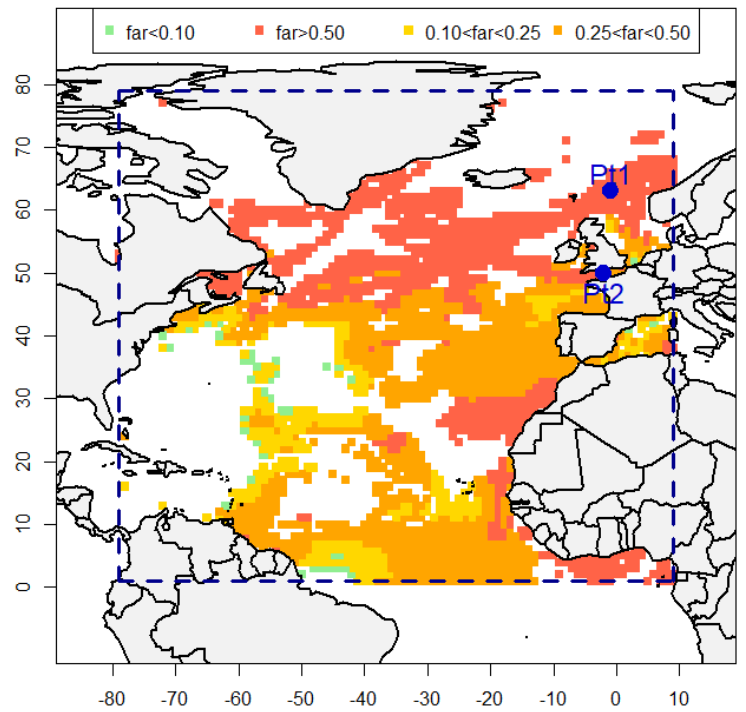

Figure 5. Update of Figure 4 by only considering the spatial locations where the p-value of the test by Cox and Oates (1984) is larger than 5\%.

\section{CONCLUSIONS}

The present study has focused on EEA for wave record breaking i.e. the occurrence of an extreme $h s$ value that exceeds all past observations over the whole North Atlantic Ocean Basin (NAOB). The estimates of the fraction of attributable risk far together with the analysis of the different sources of uncertainties (EEA assumptions, statistical, and use of hindcast 
data) indicate that the northern part of NOAB present significant far estimates superior to $50 \%$ (with high confidence), more specifically along the northern Canadian, Scottish and southwestern Norwegian coasts (over the latitudes $50^{\circ}-65^{\circ} \mathrm{N}$ ). These findings should be considered evidence that the processes / factors acting in the factual worlds (here 1978-2008) have led to changes of the probability of the $h s$ breaking records (w.r.t. the counterfactual world 1900-1930). This finding brings an additional element, which is consistent (especially in the northern part of NAOB) with the conclusions by Young and Ribal (2019), who highlighted the increase in high-percentile $h s$ over the period 1985-2018 using satellite observations.

Yet, the present study tells nothing about the physical processes that have led to such changes. A complementary analysis should focus on the link between climate ensemble runs and high-resolution ocean models to derive $h s$ data where the effect of greenhouse gas emissions have been removed, but with the need to address the difficulties in the setup of counterfactual runs (see discussion by Naveau et al. 2019: Sect.3.2). In this view, intiatives like Morim et al. (2019), Reguero et al. (2019) and Mentaschi et al. (2017) should thus be intensified and properly combined with ensemble runs in the future.

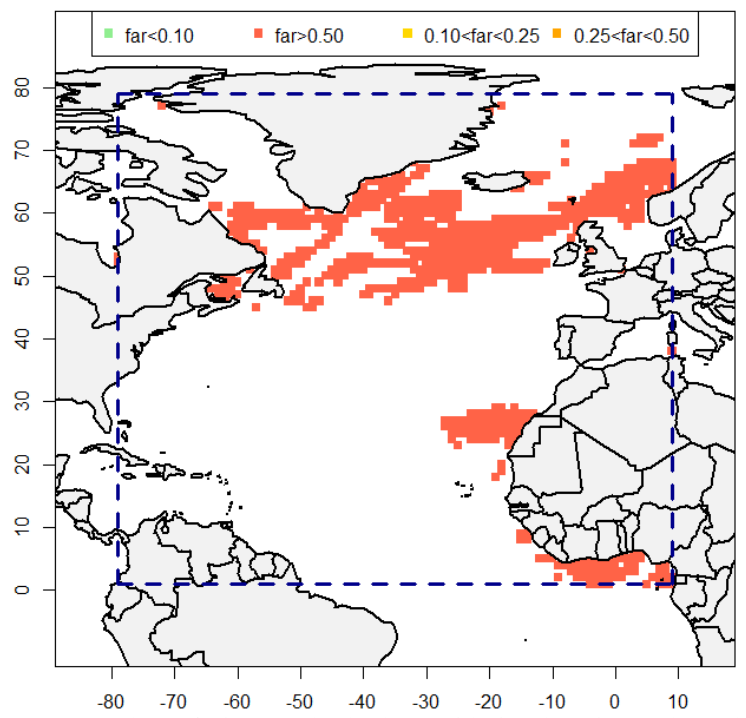

Figure 6. Update of Figure 5 by both considering locations where the pvalue of the test by Cox and Oates (1984) is larger than 5\% and where the lower bound of the $90 \%$-confidence interval exceeds zero.

\section{ACKNOWLEDGMENTS}

We acknowledge financial support of Project EUPHEME, which is part of ERA4CS, an ERA-365 NET initiated by JPI Climate, and funded by FORMAS (SE), BMBF (DE), BMWFW (AT), 366 IFD (DK), MINECO (ES), ANR (FR) with cofunding by the European Union (Grant 690462). The R script for implementing the EEA of Naveau et al. (2018) is available at: https://thaos.github.io/farr_vignette/. The wave data are available at https://www.sonel.org/-Waves-.html.

\section{LITERATURE CITED}

Bertin, X.; Prouteau, E.; and Letetrel, C., 2013. A significant increase in wave height in the North Atlantic Ocean over the 20th century. Global and Planetary Change, 106, 7783.

Bindoff, N.L.; et al. 2013. Detection and Attribution of Climate Change: from Global to Regional. In: Climate Change 2013: The Physical Science Basis. Contribution of Working Group I to the Fifth Assessment Report of the Intergovernmental Panel on Climate Change [Stocker, T.F.; et al. (eds.)]. Cambridge University Press, Cambridge, United Kingdom and New York, NY, USA.

Compo, G.P.; et al., 2011. The twentieth century reanalysis project Quarterly Journal of the Royal Meteorological Society. 137, 1-28

Dodet, G.; Bertin, X.; and Taborda, R., 2010. Wave climate variability in the North-East Atlantic Ocean over the last six decades. Ocean Modelling 31, 120-131.

Fortunato, A.B., et al., 2017. A numerical study of the February 15, 1941 storm in the Tagus estuary. Continental Shelf Research 144, 50-64.

Gulev, S.K.; and Grigorieva, V., 2004. Last century changes in ocean wind wave height from global visual wave data. Geophysical Research Letters, 31(24).

Hauser, M.; et al., 2017. Methods and model dependency of extreme event attribution: the 2015 European drought. Earth's Future, 5, 1034-1043.

Jézéquel, A.; et al., P.; 2018. Behind the veil of extreme event attribution. Climatic Change, 149, 367-383.

Mentaschi, L.; et al., 2017. Global changes of extreme coastal wave energy fluxes triggered by intensified teleconnection patterns. Geophysical Research Letters, 44(5), 2416-2426.

Morim, J. et al., 2019. Robustness and uncertainties in global multivariate wind-wave climate projections. Nature Climate Change, 1-8.

Naveau, P.; Ribes, A.; Zwiers, F.; Hannart, A.; Tuel, A.; and Yiou, P., 2018. Revising Return Periods for Record Events in a Climate Event Attribution Context. Journal of Climate, 31, 3411-3422.

Naveau,P.; Hannart, A.; Ribes, A., 2019. Statistical methods for extreme event attribution in climate science. Annual Review of Statistics and Its Application

Otto, F.E.; Massey, N.; van Oldenborgh, G.J.; Jones, R.G.; and Allen, M.R., 2012. Reconciling two approaches to attribution of the 2010 Russian heat wave. Geophysical Research Letters, 39(4).

Reguero, B.G.; Losada, I.J.; and Méndez, F.J.; 2019. A recent increase in global wave power as a consequence of oceanic warming. Nature communications, 10.

Stott, Peter A.; et al., 2016. Attribution of Extreme Weather and Climate-Related Events: Attribution of Extreme Weather and Climate-Related Events. Wiley Interdisciplinary Reviews: Climate Change, 7, 23-41.

van Oldenborgh, G.J.; et al., (2017). Attribution of extreme rainfall from Hurricane Harvey, August 2017. Environmental Research Letters, 12, 124009. 
Young, I.R.; and Ribal, A., 2019. Multiplatform evaluation of global trends in wind speed and wave height. Science, 364(6440), 548-552. 